\title{
Local immunoglobulin production is different in gastritis associated with dermatitis herpetiformis and simple gastritis
}

\author{
K VALNES, P BRANDTZAEG, K ELGJO, R STAVE, K BAKLIEN, \\ AND O FAUSA
}

From the Laboratory for Immunohistochemistry and Immunopathology, Institute of Pathology, and Department of Internal Medicine A, University of Oslo, The National Hospital, Rikshospitalet; Department of Internal Medicine and Blood Bank and Department of Immunology, Ullevål Hospital, Oslo, Norway

SUMMARY The degree of inflammation and atrophy in gastric body mucosal specimens $(\mathrm{n}=38)$ from 28 patients with dermatitis herpetiformis $(\mathrm{DH})$ was graded histologically. Immunoglobulin (Ig) producing cells were enumerated by paired immunofluorescence staining in a $500 \mu \mathrm{m}$ wide section area from the muscularis mucosae to the lumen (mucosal 'tissue unit'). The number of immunocytes of the three main classes (IgA, IgM, and IgG) was significantly raised with increasing degree of gastritis. All three classes were increased in specimens showing atrophy compared with those without atrophy. IgA cells predominated as in simple gastritis, but a striking difference was a marked increase of IgM cells in specimens with the most pronounced DH-associated gastritis. Relative class distribution of immunocytes within different mucosal zones showed that the percentage of IgA cells was significantly higher in the luminal than in the basal zone, whereas the contrary was true for IgG cells. IgM cells did not show any zonal preference. No relation was seen between small bowel and gastric lesions. The disproportionate increase of gastric IgM producing cells in DH might nevertheless reflect seeding of precursor cells of the secretory immune system generated in the proximal small intestine where the local IgM response is relatively pronounced.

Occurrence of gluten sensitive enteropathy in patients with dermatitis herpetiformis $(\mathrm{DH})$ is well documented.' The additional presence of a gastric lesion was first indicated when circulating antibodies to parietal cells were found in such patients. ${ }^{2} \mathrm{~A}$ high prevalence of gastric acid hyposecretion and atrophic gastritis associated with DH was later confirmed in several studies. ${ }^{3-9}$

The DH related atrophic gastritis has much in common with that found in pernicious anaemia, both in terms of severity, localisation to the gastric body, and a possible autoimmune pathogenesis. Auto-

Address for correspondence: Dr Kolbjørn Valnes, LIIPAT, Rikshospitalet, 0027 Oslo 1, Norway.

Received for publication 12 May 1987 immune gastritis of pernicious anaemia and other disorders cannot be distinguished from severe atrophic gastritis in patients with dyspeptic diseases by conventional histological examination. ${ }^{10}$ In a previous study of normal and diseased gastric mucosa we showed that immunoglobulin A (IgA) producing cells always predominated, indicating a highly activated secretory immune system." A severe degree of simple chronic gastritis and glandular atrophy, however, was associated with disproportionately increased local production of IgG." Although IgG is probably of significance in the gastric mucosa in terms of internal or 'second line' defence it may, at the same time, contribute to the pathogenesis of gastritis through immunopathological mechanisms.

The aim of the present study was to characterise such immunological features in the gastric mucosa of 
patients with $\mathrm{DH}$ as nothing apparently was known about $\mathrm{DH}$-associated gastritis in this respect.

\section{Methods}

SAMPLING AND TISSUE PREPARATION

Gastric body tissue specimens $(n=38)$ were obtained through a radiographically controlled multiple biopsy capsule from nine women and 19 men with DH (median age, 51 years; range, 14-69 years). The diagnosis of $\mathrm{DH}$ was based on clinical and histological criteria and on the presence of IgA deposits in uninvolved skin. ${ }^{12}$ In 22 of the patients intestinal biopsy specimens were examined for histological grading of the intestinal lesion. Blood samples for determination of serum autoantibodies were obtained from 21 of the patients (matched for age and sex).

Body mucosal specimens $(n=117)$ of simple gastritis associated with various disorders described elsewhere ${ }^{11}$ were used as controls. Of the latter material altogether 13 specimens obtained from seven women and four men (median age, 40 years; range, 28-54 years) with untreated coeliac disease (CD) were separately studied in comparison with the $\mathrm{DH}$ specimens.

All tissue specimens were prewashed in isotonic phosphate buffered saline (PBS; $0.01 \mathrm{M}$ phosphate buffer, $\mathrm{pH} 7 \cdot 6$, containing $0 \cdot 15 \mathrm{M} \mathrm{NaCl}$ ) for 48 hours at $4^{\circ} \mathrm{C}$ to remove extracellular $\mathrm{Ig}$ and processed by cold ethanol fixation and embedding in paraffin..$^{13}$

\section{IMMUNOHISTOCHEMICAL PROCEDURES AND}

TESTS FOR AUTOANTIBODIES

The characteristics and applied combinations of fluorochrome conjugates have been reported previously. "Immunocytes of two different cytoplasmic Ig classes were counted by paired direct immunofluorescence (DIF) staining in the same tissue section. The three major classes (IgA, IgM, and $\operatorname{IgG}$ ) were identified by means of both a fluorescein isothiocyanate (FITC) and a tetramethylrhodamine isothiocyanate (TRITC) conjugate in serial sections cut at $6 \mu \mathrm{m}$ from each specimen, whereas $\operatorname{IgD}$ and $\operatorname{IgE}$ were stained concurrently in a single section with TRITC and FITC conjugate, respectively.

Indirect immunofluorescence test on cryostat sections of rat tissues was used for detection of serum autoantibodies to nuclear (ANA), smooth muscle (SMA), mitochondrial (AMA) and gastric parietal cell (GPC) antigens. Similar testing for autoantibodies to adrenal cortex (AC) antigens was done on human adrenal tissue. Antibodies to thyroglobulin (THG) and thyroid microsomal (THM) antigens were detected by passive haemagglutination technique using commercially available kits (Thymune $T$ and Thymune M, Wellcome Reagents Ltd, Beckenham, England).

MICROSCOPY, CELL COUNTING AND

EVALUATION OF RESUITS

Histopathological classification of the gastric specimens was based on conventional microscopy of serial sections stained with a haematoxylin, azophloxine and saffron (HAS) trichrome method ${ }^{1+}$ as described elsewhere. ${ }^{15}$ This evaluation was carried out blindly by another observer who graded the gastric material according to inflammatory index (0-3) and atrophy $(0-2) .{ }^{16}$ The intestinal specimens were categorised in three groups by stereomicroscopy and histology: group I (normal or minor abnormality), group II (intermediate abnormality), and group III (major abnormality). ${ }^{17}$

Direct immunofluorescence stained tissue sections were examined and photographed in a Leitz Orthoplan microscope equipped with a Ploem-type vertical illuminator. Counting of Ig producing immunocytes (purely red or green cytoplasmic staining) was done by projecting double exposed colour slides at a final magnification of $\times 500$. The counts were based on a $500 \mu \mathrm{m}$ wide mucosal 'tissue unit' including the full height of the mucosa. ${ }^{1 x}$ A $200 \mu \mathrm{m}$ luminal zone and a remaining basal zone of this unit were evaluated separately. "Comparison of cell counts was done by Wilcoxon's test for unpaired samples (two-tailed) with a chosen level of significance at $5 \%$.

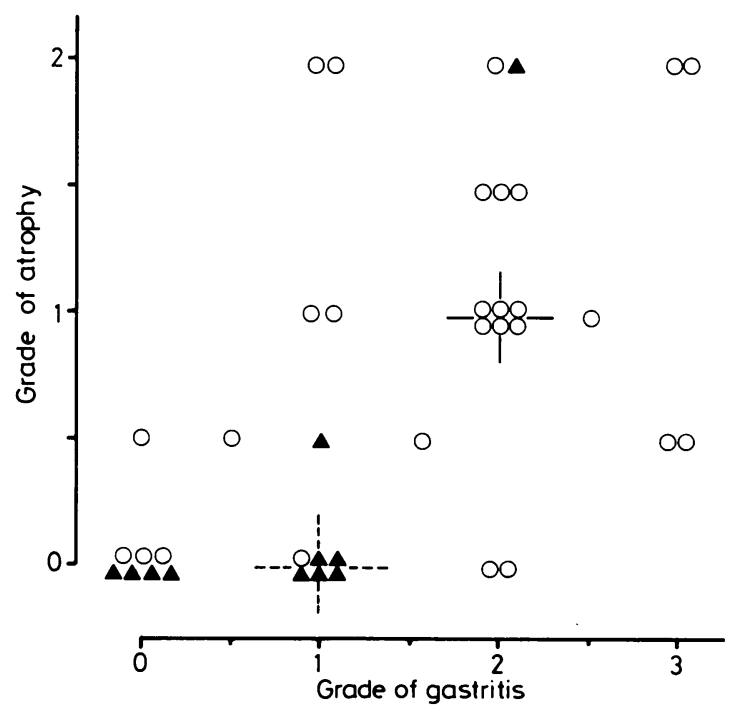

Fig. 1 Distribution of patients with dermatitis herpetiformis $(D H)(O)$ or coeliac disease $(C D)(\mathbf{\Delta})$ according to grade of body gastritis and atrophy. For each patient, these changes were based on evaluation of one to three specimens. Medians indicated by horizontal and vertical lines $(D H$, solid; $C D$, dashed). 


\section{Results}

Both inflammatory changes and atrophy in the gastric body were significantly more pronounced in $\mathrm{DH}$ than in CD (Fig. 1). In CD these gastric body histopathological changes were similar to those seen in patients with gastric and duodenal ulcer or various other disorders."

Ig producing cells of the three main classes were clearly visualised with green and red fluorescence by paired DIF staining. Cells with cytoplasmic IgD and IgE were occasionally seen but were discounted because of their small number $(<1 \%)$.

\section{Ig PRODUCING CELLS RELATED TO GRADE OF GASTRITIS}

Both totally and within each mucosal zone of the DH specimens the number of Ig producing cells increased significantly from gastritis grade 0 to grade 2 and also from grade 1 to grade 3 (Fig. 2). Compared with the other immunocyte classes, however, the increase of IgM cells in grades 2 and 3 was strikingly disproportionate (Table).

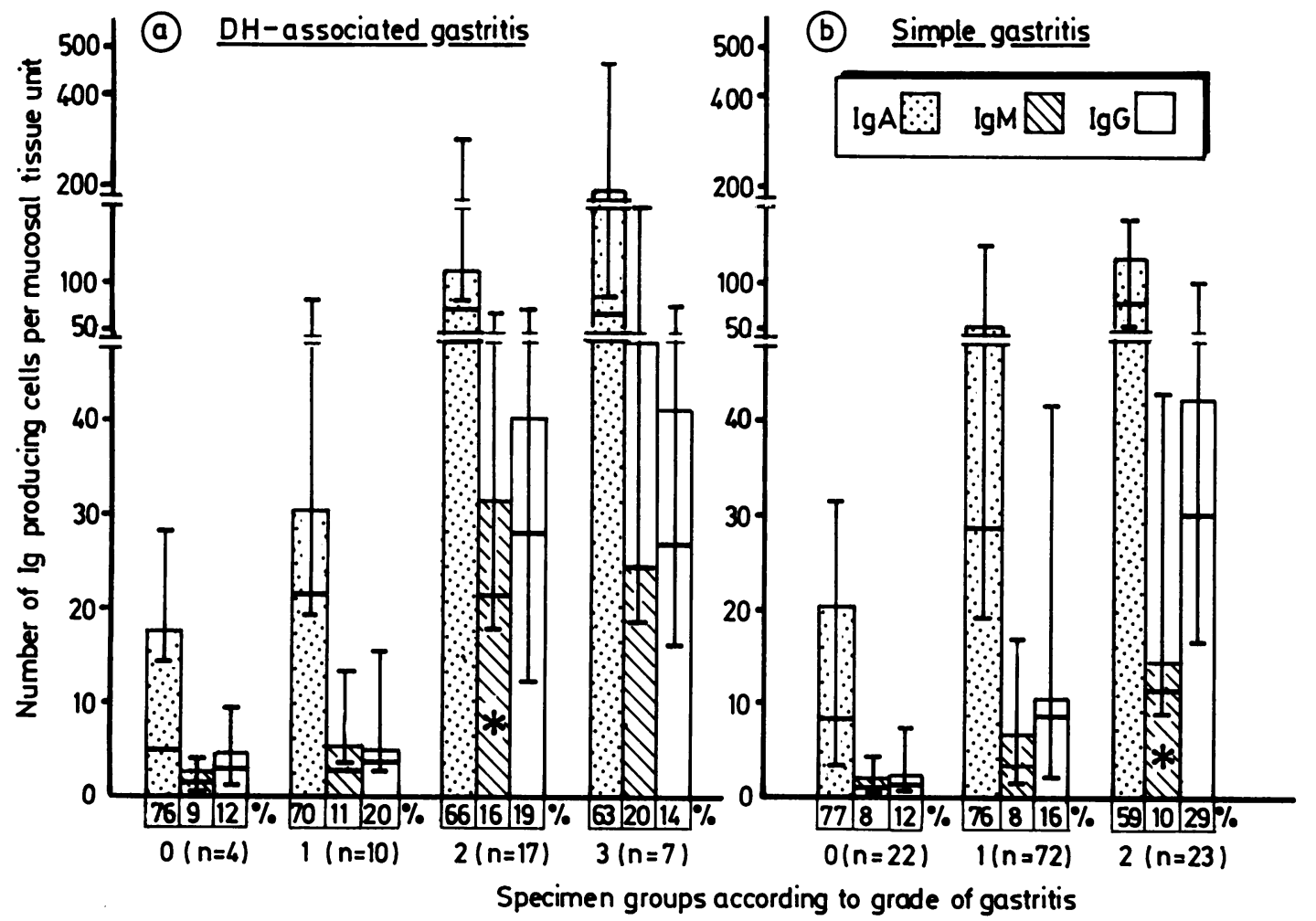

Fig. 2 Median total number and $95 \%$ confidence interval (range for $n=4$ and $n=7$ ) of $\operatorname{Ig} A, \operatorname{Ig} M$, and IgG producing cells per mucosal 'tissue unit' in gastric body specimens from patients with DH associated (a) and simple gastritis (b) in relation to grade of gastritis. Upper and lower parts of columns indicate median cell numbers in luminal and basal zones, respectively (see text). Percentage class distribution of immunocytes is given below the columns. $n=$ number of specimens. Significant differences between DH associated and simple gastritis in total number of cells is indicated $\left({ }^{*}\right)$.

Table Numeric increase factors for IgA, IgM and IgG producing cells in gastric body specimens graded histopathologically according to degree of inflammation in patients with dermatitis herpetiformis $(\mathrm{DH})$ or simple gastritis $(S G)$ *

\begin{tabular}{|c|c|c|c|c|c|c|}
\hline \multirow{2}{*}{$\begin{array}{l}\text { Grade of } \\
\text { gastritis }\end{array}$} & \multicolumn{2}{|l|}{$\lg A$} & \multicolumn{2}{|l|}{$\lg M$} & \multicolumn{2}{|l|}{$\operatorname{Ig} G$} \\
\hline & $D H$ & $S G$ & $D H$ & $S G$ & $D H$ & $S G$ \\
\hline Grade 1 & 1.7 & $2 \cdot 2$ & 1.9 & $2 \cdot 8$ & $1 \cdot 1$ & $4 \cdot 3$ \\
\hline Grade 2 & $6 \cdot 3$ & $5 \cdot 5$ & $12 \cdot 0$ & 6.5 & $9 \cdot 5$ & $18 \cdot 5$ \\
\hline Grade 3 & 10.9 & & $18 \cdot 6$ & & 9.7 & \\
\hline
\end{tabular}

${ }^{*}$ Numeric increase factors represent relative increase of Ig producing cells per mucosal 'tissue unit' compared with specimens without inflammation (grade ()) in subjects with or without DH, respectively.

No differences in immunocyte numbers were found when specimens of gastritis grade 0 and 1 in the DH material were compared with the corresponding grades in all patients with simple gastritis (Fig. 2) or in those with concurrent $\mathrm{CD}$. Conversely, in gastritis grade 2 the number of IgM cells was significantly 


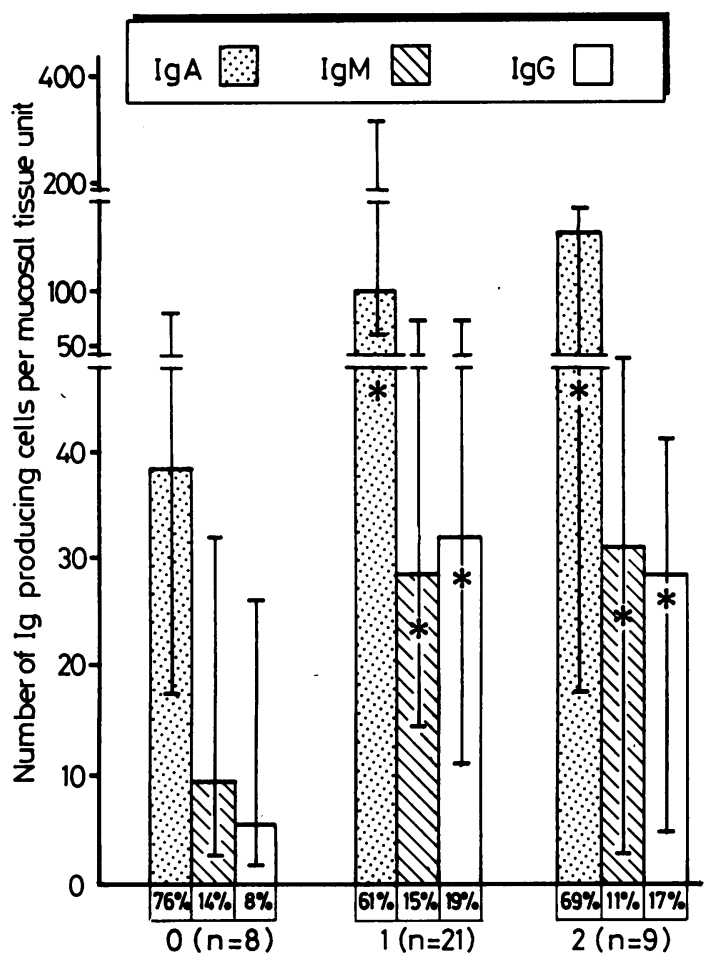

Fig. 3 Median number (and $95 \%$ confidence interval) of IgA, IgM, and IgG producing cells per mucosal 'tissue unit' in gastric body specimens from patients with $D H$ in relation to grade of atrophy. Percentage class distribution of immunocytes is given below the columns. Significant numeric increase compared with grade 0 is indicated $\left({ }^{*}\right)$.

increased in DH compared with simple gastritis - that is, $31 v 14.3$ cells per mucosal 'tissue unit' (Fig. 2). No such comparison could be done for grade 3 because the simple gastritis material did not contain specimens with that grade.

Relative class distribution of immunocytes within different mucosal zones showed in all gastritis groups that the percentage of IgA cells was significantly higher in the luminal than in the basal zone, whereas the contrary was true for IgG cells. IgM cells did not show any zonal preference.

\section{DISTRIBUTION OF Ig PRODUCING CELLS}

RELATED TO GRADE OF GLANDULAR ATROPHY A significantly increased number of all three immunocyte classes was found when specimens without atrophy were compared with those showing atrophy of grade 1 (Fig. 3). No further increase was observed for grade 2, apparently because the height of the mucosal 'tissue unit' was reduced. The percentage class distribution was similar in groups with different grades of atrophy (Fig. 3).

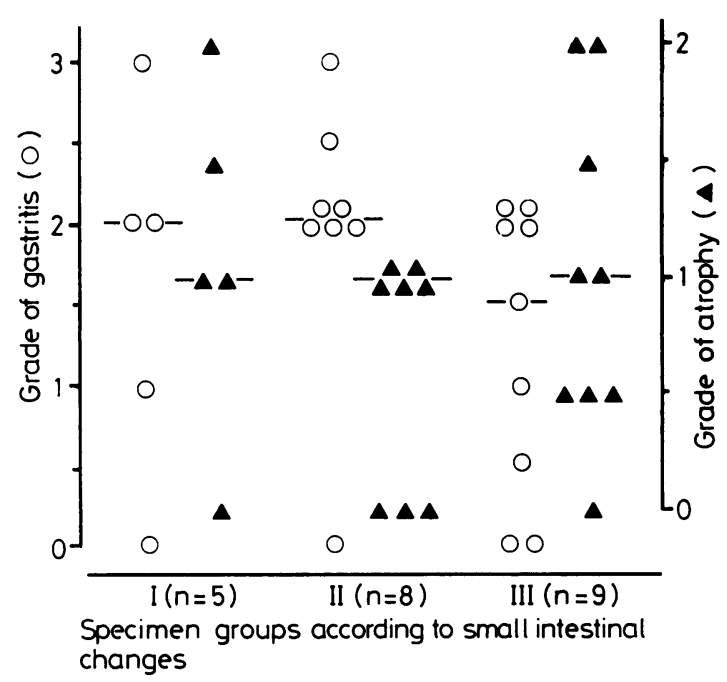

Fig. 4 Relation between distribution of gastric inflammatory index $(\bigcirc)$ and atrophy $(\mathbf{\Delta})$ in 22 patients with DH with three grades of small intestinal changes (see text). Medians are indicated by horizontal lines.

GASTRIC LESION RELATED TO SMALL

INTESTINAL MORPHOLOGY

In 22 patients gastric and small intestinal morphology could be compared. The inflammatory and atrophic indices for each patient were based on single or multiple tissue sections from 1 to 4 specimens. No relationship was found between gastric and small intestinal lesions (Fig. 4).

\section{AUTOANTIBODIES IN SERUM}

Gastric parietal cell (GPC) antibodies were detected in three of the 21 patients tested; two had in addition ANA, AC, and THM antibodies. SMA antibodies were detected in two patients and THG and THM antibodies in one patient. Four other patients showed weakly positive reactions against THM. In 10 patients with $C D(n=4)$ or non-ulcer dyspepsia $(n=$ 6) no autoantibodies were detected.

\section{Discussion}

IgA was the predominating class of mucosal immunocytes regardless of the severity of the gastric lesion associated with DH. This feature was consistent with our previously reported results in patients with unspecified 'simple' gastritis." The most remarkable finding in DH gastritis was a substantial number of IgM producing cells in specimens with the two highest inflammatory grades $(16 \%$ and $20 \%$ of the immunocytes, respectively). Expressed by numeric increase factors compared with normal mucosa, IgM cells showed the most pronounced rise 
in all inflammatory groups. This was different from simple gastritis and has to our knowledge not been reported previously.

Locally produced $\operatorname{IgA}$ and $\operatorname{IgM}$ contribute to secretory immunity ${ }^{19}$ but the antigenic stimulus underlying the pronounced gastric IgM response in DH is unknown. It is interesting in this respect that there is an increased number of IgM producing cells in the duodenal mucosa of DH patients who are not on a gluten free diet compared with those who are. ."21 $^{211}$ None of our patients was on a gluten free diet when biopsy was carried out.

The subclass distribution of $\operatorname{IgA}$ producing cells has indicated a closer relationship between the secretory immune system of the gastric and duodenal mucosa than between the proximal and distal intestine. ${ }^{22}$ No histopathological relationship was found, however, between the gastric and the small intestinal lesions in this study, which is in keeping with other reports. ${ }^{3669}$ Moreover, a recent study showed that the gastric lesion did not improve during gluten free diet..$^{23}$ This indicates that disturbed small bowel function is not the cause of the gastric abnormality. Several other possibilities have been discussed, such as iron, zinc or other trace metal deficiencies, genetic factors or Dapsone treatment. ${ }^{4}$

IgM antibodies can activate complement and may thereby contribute to the chronicity of gastritis and glandular atrophy. A higher degree of systemic complement activation has been observed in patients with DH who are not on gluten free diet compared with those who are. ${ }^{24}$ With intensified gastritis an increase of $\mathrm{IgG}$ cells in gastric body mucosa of patients with $\mathrm{DH}$ indicated altered mucosal immunologic homeostasis. ${ }^{25}$ It is of interest in this context that local $\mathrm{IgG}$ cells with antibody specificity for intrinsic factor have been observed in pernicious anaemia. ${ }^{26}$ Dermatitis herpetiformis patients with gastric lesions have a higher prevalence of parietal cell (GPC) antibodies than those without gastric atrophy, ${ }^{8}$ suggesting that an autoimmune mechanism may be involved in the pathogenesis. The occurrence of GPC and thyroid autoantibodies in the present DH material corresponded roughly to other reports. ${ }^{27}$

Our finding of a higher degree of inflammation and atrophy in the body mucosa of patients with $\mathrm{DH}$ than in those with $\mathrm{CD}$ is in keeping with previous studies. ${ }^{54}$ This difference is also true after adjustment for age. ${ }^{9}$ Patients with CD may have increased prevalence of gastric acid hyposecretion and gastric atrophy, ${ }^{2 .}$ however, although other studies have indicated a relative low prevalence of achlorhydria. ${ }^{24.31}$

The gastric lesion in $\mathrm{DH}$, along with the skin lesion (for review, see ref 27), is the most important difference between $\mathrm{DH}$ and $\mathrm{CD}$. It is not known whether there is any relationship between the gastric lesion and the skin lesion. Moreover, the role of circulating immune complexes in the pathogenesis of $\mathrm{DH}$ is not clear. ${ }^{31-33}$ It is interesting that the skin deposits contain dimeric $\operatorname{IgA}$ of the IgA1 subclass, ${ }^{3+}$ compatible with an origin from gastric and duodenal plasma cells."2

This study confirms previous reports that severe atrophic body gastritis is frequently associated with DH without being related to the severity of the small bowel lesion. The overall pattern of local Ig production in DH associated gastritis corresponded to that seen in simple gastritis with the exception of a remarkably disproportionate increase of gastric IgM producing cells in DH. This might reflect seeding of precursor cells of the secretory immune system generated in the proximal small intestine where the local IgM response is relatively pronounced. As there is no evidence for gluten involvement, autoantigens may, instead, partly explain the persistent immunopathology of $\mathrm{DH}$ associated gastritis.

\section{References}

1 Marks J, Shustu S, Watson AJ. Small-bowel changes in dermatitis herpetiformis. Lancet 1966; ii: 1280-2.

2 Fraser NG. Autoantibodies in dermatitis herpetiformis. Br J Dermatol 1970; 83: 609-13.

3 Andersson H, Dotevall G, Mobacken H. Gastric secretion of acid and intrinsic factor in dermatitis herpetiformis. Scand J Gastroenterol 1971; 6: 411-6.

4 Lancaster-Smith MJ, Kumar PJ, Johnson GD. Atrophic gastritis and dermatitis herpetiformis. Lancet 1974; ii: 777.

5 Fausa O, Eeg Larsen T, Husby G, Thune P. Gastrointestinal investigations in dermatitis herpetiformis. Acta Dermatovener (Stockh) 1975; 55: 203-6.

6 O'Donoghue DP, Lancaster-Smith M, Johnson GD, Kumar PJ. Gastric lesion in dermatitis herpetiformis. Gut 1976; 17: 185-8.

7 Stockbrügger R, Andersson H, Gillberg R, Kastrup W, Lundquist G, Mobacken H. Auto-immune atrophic gastritis in patients with dermatitis herpetiformis. Acta Dermatovener (Stockh) 1976; 56: 111-3.

8 Stockbrügger R, Kastrup W, Lundquist G, Mobacken $\mathrm{H}$. Development of gastric dysfunction in dermatitis herpetiformis. Acta Dermatovener (Stockh) 1978; 58: 343-8.

9 Gillberg R, Kastrup W, Mobacken H, Stockbrügger R, Åhsen C. Gastric morphology and function in dermatitis herpetiformis and in coeliac disease. Scand J Gastroenterol 1985; 20: 133-40.

10 Coghill NF, Doniach O, Roitt IM, Mollin DL, Wynn Williams A. Autoantibodies in simple atrophic gastritis. Gut 1965; 6: 48-56.

11 Valnes K, Brandtzaeg P, Elgjo K, Stave R. Quantitative distribution of immunoglobulin-producing cells in gastric mucosa: relation to chronic gastritis and glandular atrophy. Gut 1986; 27: 505-14. 
12 Fry L. Seah PP. Dermatitis herpetiformis: an evaluation of diagnostic criteria. Br J Dermatol 1974; 90: 137-46.

13 Brandtzaeg P. Mucosal and glandular distribution of immunoglobulin compounds. Immunohistochemistry with a cold ethanol-fixation technique. Immunology 1974; 26: 1101-14.

14 Stave R, Brandtzaeg P. Fluorescence staining of gastric mucosa. A study with special reference to parietal cells. Scand J Gastroenterol 1977; 12: 885-91.

15 Valnes K, Brandtzaeg P, Elgjo K, Stave R. Specific and non-specific human defense factors in the epithelium of normal and inflamed gastric mucosa. Immunohistochemical localization of immunoglobulins, secretory component, lysozyme, and lactoferrin. Gastroenterology 1984; 86: 402-12.

16 Rao SS, Krasner N, Thomsen TJ. Chronic gastritis - a simple classification. J Pathol 1975; 117: 93-6.

17 Baklien K, Fausa O, Thune PO, Gjone E. Immunoglobulins in jejunal mucosa and serum from patients with dermatitis herpetiformis. Scand J Gastroenterol 1977; 12: 161-8.

18 Brandtzaeg P, Baklien K, Fausa O, Hoel PS. Immunohistochemical characterization of local immunoglobulin formation in ulcerative colitis. Gastroenterology 1974; 66: $1123-36$.

19 Brandtzaeg $\mathrm{P}$. Role of $\mathrm{J}$ chain and secretory component in receptor-mediated glandular and hepatic transport of immunoglobulins in man. Scand J Immunol 1985; 22: 111-46.

20 Lancaster-Smith $\mathrm{M}$, Joyce S, Kumar P. Immunoglobulins in the jejunal mucosa in adult coeliac disease and dermatitis herpetiformis after the reintroduction of dietary gluten. Gut 1977; 18: 887-91.

21 Vermeer BJ, Lindeman J, van der Harst-Oostveen CJGR, Pena AS, van Vloten WA. The immunoglobulin-bearing cells in the lamina propria and the clinical response to a gluten-free diet in dermatitis herpetiformis. Arch Derm Res 1977; 258: 223-30.

22 Kett K, Brandtzaeg P, Radl J, Haaijman J. Different subclass-distribution of $\operatorname{IgA}$-producing cells in human lymphoid organs and various secretory tissues. $J$ Immunol 1986; 136: 3631-5.

23 Kastrup W, Andersson H, Gulberg R, Mobacken H, Stockbrügger $\mathbf{R}$. Influence of gluten-free diet on the gastric condition in dermatitis herpetiformis. Scand $J$ Gastroenterol 1985; 20: 39-45.

24 Teisberg P, Baklien K, Fausa O, Thune PO. Mediator mechanisms of humoral immunity in patients with dermatitis herpetiformis and enteropathy. Scand $J$ Gastroenterol 1976; 11: suppl 38: 21.

25 Brandtzaeg P, Valnes K, Scott H, Rognum TO, Bjerke $\mathrm{K}$, Baklien $\mathrm{K}$. The human gastrointestinal secretory immune system in health and disease. Scand J Gastroenterol 1985; 20: suppl 114: 17-38.

26 Baur S, Koo N, Taylor KB. The immunoglobulin class of autoantibodies-containing cells in the gastric mucosa. Immunology 1970; 19: 891-4.

27 Katz SI. Dermatitis herpetiformis: the skin and the gut. Ann Intern Med 1980; 93: 857-74.

28 Hansky J, Shiner M. Gastric studies in idiopathic steatorrhea. Gastroenterology 1964; 45: 49-56.

29 Fausa $O$. Vitamin $\mathbf{B}_{12}$ absorption in intestinal diseases. Scand J Gastroenterol 1974; 9: suppl 29: 75-9.

30 Bossak ET, Wang CI, Adlersberg D. Clinical aspects of the malabsorption syndrome (idiopathic sprue). $J \mathbf{M t}$ Sinai Hosp 1957; 24: 286-303.

31 Mowbray JF, Hoffbrand AV, Holborow EJ, Seah PP, Fry L. Circulating immune complexes in dermatitis herpetiformis. Lancet 1973; i: 400-2.

32 Mohammed I, Holborow EJ, Fry L, Thompson BR, Hoffbrand AV, Stewart JS. Multiple immune complexes and hypocomplementaemia in dermatitis herpetiformis and coeliac disease. Lancet 1976; ii: 487-90.

33 Zone JJ, Bernard A, La Salle BS, Provost TT. Induction of IgA circulating immune complexes after wheat feeding in dermatitis herpetiformis patients. J Invest Dermatol 1982; 78: 375-80.

34 Unsworth DJ, Payne AW, Leonard JN, Fry L, Holborow $\mathrm{EJ}$. IgA in dermatitis herpetiformis skin is dimeric. Lancet 1982; i: 478-80. 